\title{
HUELLA Y PRESENCIA FLAMENCA E ITALIANA EN LOS CONVENTOS CORDOBESES DE MADRES DOMINICAS
}

\author{
Francisco Manuel Carmona Carmona \\ Universidad de Córdoba
}

Data recepción: 2018/10/02

Data aceptación: 2019/07/12

Contacto autor: aa2carcf@uco.es

ORCID: https://orcid.org/0000-0003-1118-3271

\section{RESUMEN}

Damos a conocer en esta contribución las aportaciones de obras artísticas de naturaleza o inspiración flamenca e italiana que se han conservado en los conventos de religiosas contemplativas dominicas de Madre de Dios de Baena y Jesús Crucificado de Córdoba. Fundamentamos con documentación inédita el contexto por el que estas piezas han tenido entrada en estos cenobios, además de facilitarnos la atribución de autoría a determinadas obras que hasta el momento se han mantenido en el anonimato. Así, encontramos en ellas las paternidades de los pintores Cornelis I Schut (15971655), Jan I Brueghel (1568-1625), Paul Bril (1553-1626) y Domenico Fiasella (1589-1669), y de los broncistas Sebastiano Torrigiani (†1596) y Ludovico del Duca (†1603), como también del escultor Francesco Terillus (†1635).

Palabras clave: arte conventual, dotación ornamental, tabernáculo, ermitaños, escultura en marfil

\section{ABSTRACT}

This article traces the Flemish and Italian nature or inspiration of the artworks held in the convents of the Dominican Contemplative Sisters of the Mother of God of Baena and Jesús Crucificado of Córdoba. Unpublished documentation supports evidence of the context in which these pieces entered these monasteries. We also provide information regarding the authorship of certain works that have remained anonymous to date, and thus reveal pieces by the painters Cornelis Schut (1597-1655), Jan Brueghel the Elder (1568-1625), Paul Bril (1553-1626), and Domenico Fiasella (1589-1669), the bronzists Sebastiano Torrigiani (†1596) and Ludovico del Duca (†1603), and the sculptor Francesco Terillus (†1635).

Keywords: monastic art, art collections, Eucharistic Tabernacle, hermits, ivory sculpture

La relación e influencia que los territorios europeos ejercieron sobre el arte español está suficientemente acreditada tanto de visu como por la literatura especializada. Aún hoy, la crítica histórico-artística se esfuerza por evidenciar los ideales estéticos con los que se concibieron determinadas estructuras o se crearon objetos artísticos de toda índole. No en vano, España tuvo en Italia y Flandes el mejor observatorio desde donde co- nocer, trazar e idear su particular interpretación del arte. Una realidad innegable a la que se une el gran peso político y militar que temporalmente ejerció la monarquía española en estos territorios a través de representantes procedentes del estrato alto-nobiliario'.

Los conventos cordobeses de la Segunda Orden de Santo Domingo fueron especialmente permeables a esta realidad, pues, como nos delata la 


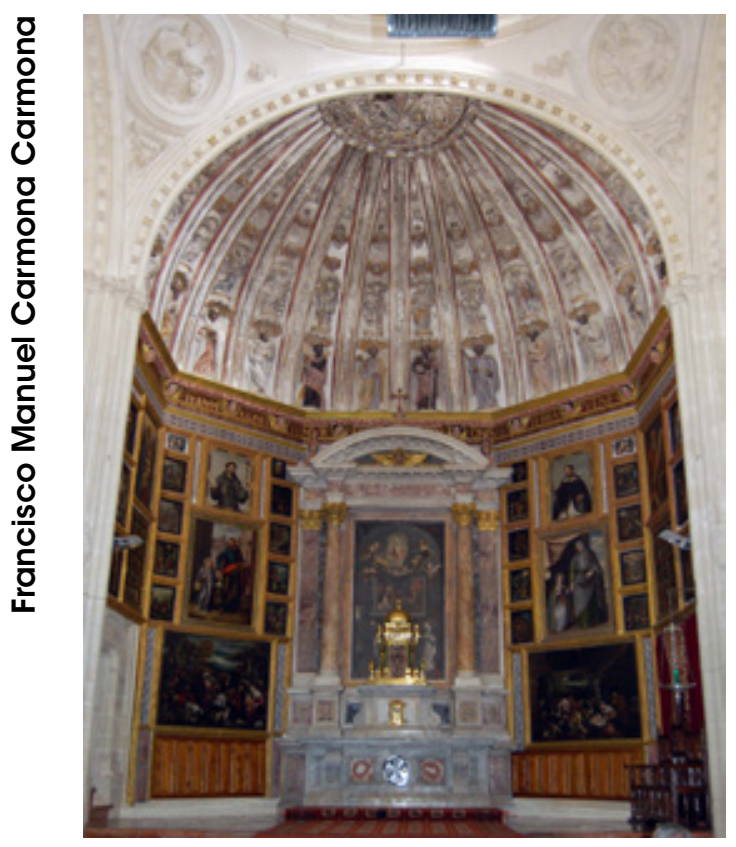

Fig. 1. Capilla mayor del convento Madre de Dios de Baena. Foto: autor

documentación manejada en los distintos fondos y archivos consultados, los de Madre de Dios en Baena y Jesús Crucificado en la capital, fueron los más favorecidos del entramado de dominicas contemplativas. Ambos se trataban de fundaciones y patronatos de destacados linajes cordobeses que desde antiguo venían desarrollando en Italia y Flandes distintos empleos del más alto nivel al servicio de la monarquía hispánica. Sin duda, ello jugó en beneficio de estos cenobios por estar constituidas sus comunidades en buena parte por féminas pertenecientes a estas familias, facilitando a través de una variada casuística el atesoramiento de numerosas piezas artísticas realizadas en estos territorios.

Amén de la vía de patronato, el fenómeno de atesoramiento artístico conventual tuvo otros cauces necesarios de reseñar. Es preciso atender al fenómeno bienhechor, con el que los conventos estudiados se constituyen en receptores de donaciones de piezas artísticas o reliquias de señaladas cualidades taumatúrgicas y claro afán de evidenciar la sacra dimensión del espacio conventual. Otra vía de atesoramiento de obras extranjeras fue el floreciente mercado artístico que constituyó Sevilla como puerto de embarque al Nuevo Mundo. La demostrada presencia de artistas flamencos e italianos en la capital hispalense, quienes a la par ejercían su arte y mercadeaban con obras ajenas, nos permite contextualizar el origen de determinada obra regalada a las religiosas a título privativo.

\section{Italia y Flandes en el convento Madre de Dios de Baena}

Este convento fue fundado en 1510 por el III conde de Cabra con la clara intención de dar solución a buena parte de las féminas de su numerosa prole mediante la toma de estado religioso. Su hijo Luis, por haber contraído matrimonio con la heredera del Gran Capitán, aportó varios estados italianos a su ya dilatada lista de señoríos castellanos, lo que a la postre propició que el ducado de Sessa se convirtiera en el vínculo primordial con Madre de Dios. Así, el V duque de Sessa, bisnieto del conde fundador, mientras ejercía el cargo de embajador cerca de la Santa Sede (1590-1604), promovió la compra-apropiación del patronato de la capilla mayor de la iglesia conventual para que sirviera de lugar de enterramiento al matrimonio ducal y su descendencia², por lo que desde Roma fue enviando obras de arte y reliquias para su adecuación ${ }^{3}$. Así pues, en un contexto de servicio a la monarquía, los duques de Sessa proveyeron a este convento de numerosas obras artísticas que fueron compradas durante su legación romana, y como nos señala la documentación manejada, con la clara intención de favorecer el establecimiento del patronato privativo de la capilla mayor.

El duque don Antonio «pidió la capilla y entierro de esta casa para que lo fuese propia y perpetua para sí con intento de adornarla, autorizarla y engrandecerla como lo comenzó a hacer desde Roma enviando el edificio y retablo que está puesto de piedra en el altar con el rico y lucido sagrario de bronce y la imagen de Nuestra Señora que le donó Clemente VIII puesta en el tabernáculo4.

Finalmente, el patronato perpetuo de la capilla lo consiguió su esposa en 1634, al haber establecido en su testamento buena parte de la dotación ornamental de la que hoy sigue haciendo gala este cenobio: 
A la señora doña Beatriz de Cardona ${ }^{5}$ un cuadro grande de Florencia y un escritorio de ébano y marfil [...] Todos los demás cuadros grandes y pequeños, de cualquier manera que sean, y todas las reliquias, y la espina de Cristo y el Eccehomo de plata dorado, y todos los ornamentos y plata de mi capilla se llevará a Madre de Dios de Baena, para adorno de la capilla del duque mi señor y mía.

Estas informaciones y otras referencias documentales y bibliográficas, nos permitirán contextualizar y ubicar las piezas artísticas de origen o inspiración italiana y flamenca que hoy atesora este convento de Baena.

1.1. ... edificio y retablo que está puesto de piedra en el altar

A poco de iniciar el $V$ duque de Sessa su embajada en la Santa Sede, se documenta el deseo de convertir la capilla mayor conventual en patronato ducal, comenzando a enviar desde Roma las distintas piezas pétreas necesarias para erigir el altar mayor de la misma. A él iban destinadas las columnas que adquirió don Antonio durante su legación, pues así se constata mediante la anotación realizada en Roma por Cesare Velli, suo secretario: "a 22 de dicembre [de 1592], 200 moneta pagati con ordine de S.E. a mr. Steffano Longo disse per prezzo de due colonne da esso compre" 7 . Este apunte contable se refiere a los fustes de travertino amarillo con que cuenta el retablo marmóreo de la capilla mayor conventual; no obstante, del resto de sus elementos arquitectónicos aún no hemos localizado el cargo y data, apoyándonos para su adscripción italiana únicamente en la documentación archivística transcrita más arriba (fig. 1).

Pese a todo, la erección del retablo debió quedar en suspenso hasta no concertarse el patronazgo privativo de la capilla mayor conventual, lo que ocurrió en 1638 gracias a la cláusula testamentaria de la duquesa doña Juana. A su hijo Luis le cupo ostentar el patronazgo de dicha capilla mayor como cabeza del linaje, pero este tenía en mente otros proyectos más magnificentes: ${ }^{8}$ pues, como nos informa una estafeta enviada al de Sessa por su maestro mayor de obras:

(sic) ... quiero adbertir a $V x^{a}$ que a muchos años que bi de unas piedras que se trajeron de Roma y estan en Baena que a mi parecer pueden serbir todas para estos entierros porque son dos portadas de jaspe con sus arquitrabes frisos $y$ cornisas y janbas de suerte que [...] me manda $V x^{a}$ ir a vivir a Baena estando alli de asiento lo dispondre de suerte que sirba todo y se gaste muy poco y sea muy lucido?.

Esta referencia demuestra que en el momento de formalizar doña Juana su testamento el retablo pétreo aún no estaba montado, como no podía ser de otro modo hasta comprometerse formal y económicamente el patronazgo; a lo que se une que la máquina arquitectónica debió dar el ajustado enmarque al cuadro de la Alegoría de la Encarnación que lo preside.

No deja de resultar paradójica la importación a Baena de piedras italianas, cuando en los mismos estados ducales y en localidades cercanas se están explotando canteras de mármoles y jaspes con gran proyección nacional ${ }^{10}$. Ello nos habla del vehículo de significación y distinción que supone para la familia comitente el traer este tipo de piezas del centro mismo del Catolicismo.

\subsection{El cuadro alegórico de la Encarnación}

Barrio Moya nos informa del inventario de bienes realizado tras la muerte de la $V$ duquesa de Sessa, en los primeros días de 1638, así como de la tasación de la colección bibliográfica y artística que poseía. De su legado testamentario el convento Madre de Dios de Baena salió muy bien parado, pues a él se destinaron todos los cuadros, reliquias, ornamentos y plata de su capilla particular madrileña, de donde se entresacan distintas piezas de origen italiano y que indudablemente tuvieron como destino este cenobio, pero ninguna alusión al cuadro que preside su capilla mayor conventual"1, lo que nos lleva a suponer que el lienzo ya era objeto de culto antes del fallecimiento de la duquesa doña Juana.

Desafortunadamente, y pese a sus dimensiones $(280 \times 165 \mathrm{~cm})^{12}$, el lienzo queda semioculto tras la enorme máquina arquitectónica del sagrario-manifestador que preside el altar mayor, no posibilitando obtener una imagen completa del mismo. No obstante, disponemos de un documento gráfico de calidad suficiente y que permite considerar por entero la composición y podamos realizar un detenido análisis, además de señalarnos lo maltrecho de su estado tras la contienda civil española (fig. 2). 


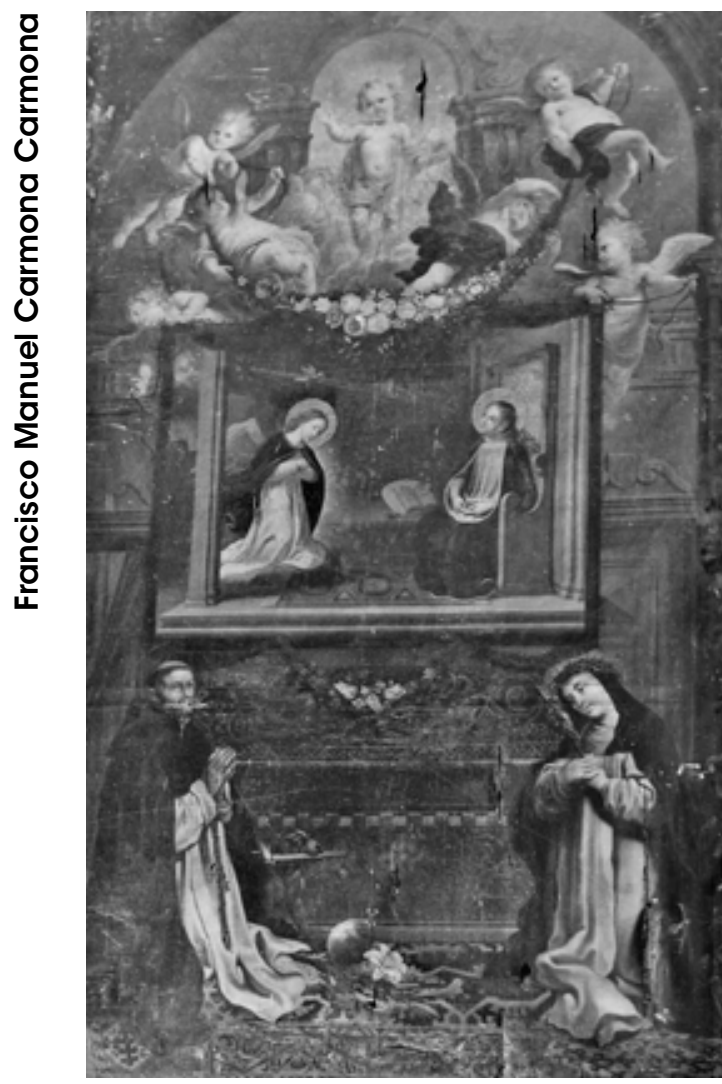

Fig. 2. Cornelis I Schut, Alegoría de la Encarnación con Santo Domingo de Guzmán y Santa Catalina de Siena, ca. 16281635. Óleo sobre lienzo, $280 \times 165 \mathrm{~cm}$. Convento Madre de Dios de Baena, retablo mayor. Foto: Archivo Diputación Provincial de Córdoba. Catálogo Histórico Artístico Provincial, Baena, ref. A-124-029

La pintura se resuelve compositivamente en tres planos. Uno central, donde con todo detalle se copia la pintura venerada en la florentina basilica della Santissima Annunziata. Otro superior, más desenvuelto, expresivo y colorista, ocupado por la imagen de un Niño Jesús Salvator Mundi entre una corte angelical que dispone guirnaldas de flores en torno al virtuoso cuadro de la Anunciación. En la inferior, se representan arrodillados e inequívocamente señalados por sus atributos a Santo Domingo de Guzmán y Santa Catalina de Siena en una actitud de contemplación divina. Sin lugar a duda el lienzo posee una categoría excepcional, original composición y una temática idónea para este emplazamiento, dado que concilia perfectamente tanto la advocación del convento -la encarnación gloriosa de Jesús, Salvador de todo el orbe- como la filiación con la representación de sus santos primordiales.

Pese a que desconocemos si el matrimonio ducal visitó la capital de la Toscana durante su estancia italiana, anima a contemplar tal posibilidad la trama de relaciones privadas en el contexto político del eje Florencia-Roma-Madrid ${ }^{13}$, así como también determinadas informaciones tangenciales que para nuestro propósito resultan esenciales; pues, la duquesa doña Juana poseía entre sus bienes dos copias de la venerada pintura florentina ${ }^{14}$, o cuanto menos, era conocedora de sus favores prodigiosos, por lo que desearía tenerla representada en una composición más complicada. Esto anima a pensar que, independientemente de que los Sessa hubiesen visitado o no la ciudad del Arno, la obra en cuestión resulta un encargo realizado exprofeso para el convento de Baena.

Sin duda, el lienzo baenense obedece a la órbita contrarreformista imperante como una Alegoría de la Encarnación con Santo Domingo de Guzmán y Santa Catalina de Siena, en la que se hace uso la arraigada tradición de la Santissima Annunziata como curiosa justificación de un cuadro dentro de otro y clave de su metafórica explicación. Además, participa del interés que se venía desarrollando desde mediados del siglo XVI por la Botánica, implantando en la composición un testimonio artístico de exaltación mariana con unas simbólicas guirnaldas multiflorales, que más allá del alarde decorativo muestran una retórica codificada y emblema de tenor espiritual y moral (fig. 3) ${ }^{15}$.

La falta de testimonio documental sobre su origen nos obliga a acudir al método de filiación estilística para acercarnos a su autor. Debió ser un pintor capaz de realizar una fiel copia de una pintura superada en estética y técnica, mostrar el realismo piadoso y la serena actitud patética de los santos de la orden, y cerrar la composición con el vaporoso rompimiento de gloria del Niño Jesús entre ángeles. Todo esto, contextualizado adecuadamente, nos señala la personalidad del pintor flamenco Cornelis I Schut (1597-1655) como autor de la Alegoría de la Encarnación de Baena conforme a los argumentos que iremos exponiendo. 


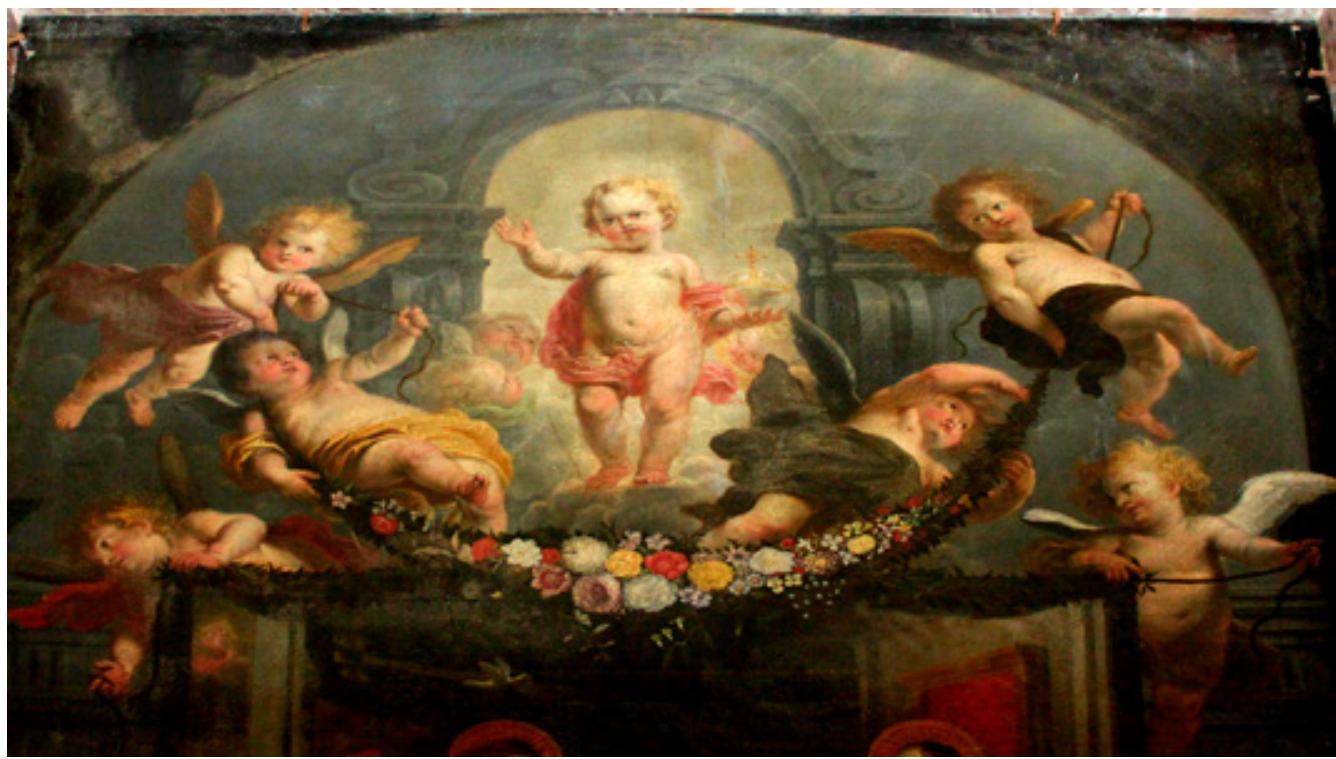

Fig. 3. Alegoría de la Encarnación con Santo Domingo de Guzmán y Santa Catalina, detalle. Convento Madre de Dios de Baena, retablo mayor. Foto: autor

A Schut el Viejo se le documenta entre 1624 y 1627 establecido en Roma, y al año siguiente en Florencia trabajando para la familia Medici, donde debió asumir la tradición de epifanías florales que acompañan a la figura y hechos de la Virgen. Aun así, es necesario señalar un nexo de unión entre el pintor de Amberes y la capilla conventual baenense: bien el comercio de arte entre España y los Países Bajos ${ }^{16}$, o bien la figura de don Gonzalo Fernández de Córdoba (15851635), hijo de los $V$ duques de Sessa, más conocido como Príncipe de Maratea o el Segundo Gran Capitán. Este, en 1632 se encuentra en los Países Bajos, soltero, sin descendencia legítima, cercano a la cincuentena de edad, por lo que es lógico pensar que colabore regalando a su madre una obra pictórica donde se representa una escena tan devota para ella, y le sirva para la decoración de la capilla que desde hace tiempo se pretende como panteón familiar ${ }^{17}$. En esos momentos el de Maratea y Schut debieron coincidir en Amberes, cuando el pintor llevaba apenas un año regresado de Italia asumiendo los preceptos artísticos impuestos por la maestría de Rubens y las nuevas tendencias temáticas:

Particularly noticeable is an increasing complexity in iconography in which two or more themes were often combined into one, or unusual motives were inserted into traditional subjects often resulting in a crowding of the picture space. In addition, new emphasis was placed on certain specific themes. Religious subjects that had gained popularity after the Council of Trent, often as a reaction to Protestant criticism, such as the Virgin and the Holy Family, the Passion, and the Sacraments continued their appeal. Certain themes, popular in earlier times, were revived. The so-called Sacra Conversazione reappeared, often in combination with a previously separate subject. Images of the Virgin and Child based on older models had been adopted by Rubens as early as the 1620's and remained popular, reflecting a renewed interest incertain medieval mystical movements such as the Devotio Moderna ${ }^{18}$.

Llama la atención la perfecta adecuación de esta alegórica representación con el trabajo elegante y refinado que realizaba Schut en sus primeras obras tras su estancia italiana, donde no dudó en incorporar los arquetipos de devoción popular romana y florentina a los requerimientos de la cada vez más cambiante estructura social flamenca y el nuevo énfasis dado al pensamiento religioso ${ }^{19}$. Por tanto, son asumibles en la Alegoría de la Encarnación baenense las referencias iconográficas, compositivas y estilísticas del jo- 

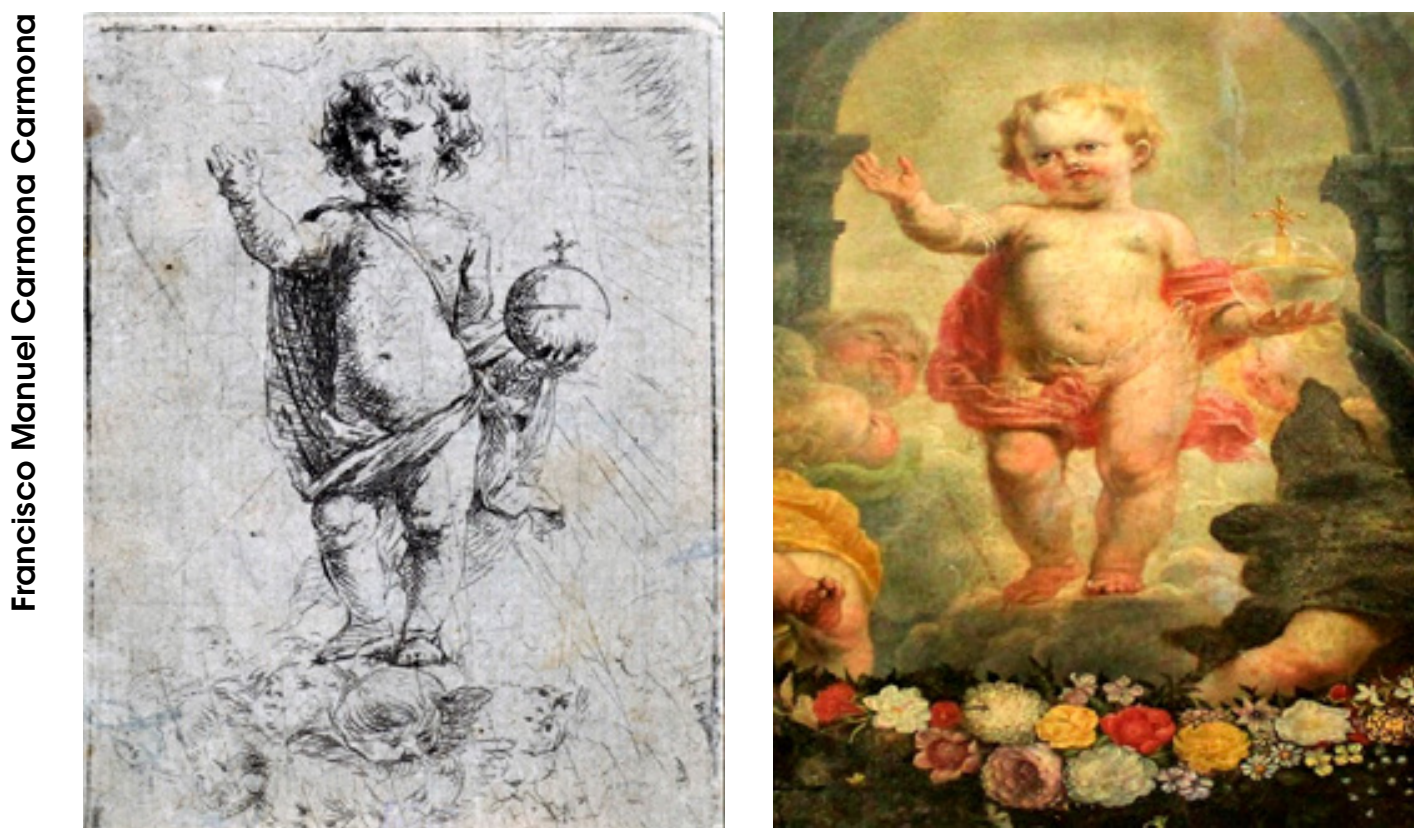

Fig. 4. Correspondencia entre Niño Jesús como Salvator Mundi de Cornelis I Schut, conservado en Rijksmuseum de Amsterdam y su homónimo representado en la Alegoría de la Encarnación. Fotos: <http://hdl.handle.net/10934/RM0001.COLLECT.173770> y del autor respectivamente

ven Schut; sobre todo en la observancia de la simetría y la manera de resolver los ángeles, de idéntica factura que su Virgen en la Gloria entre ángeles, del Museo Maagdenhuis de Amberes, o la Virgen y el Niño con Santa Isabel, San Juanito $y$ ángeles ${ }^{20}$. Ayuda a esta adscripción la peculiar forma de ocultar la desnudez de los ángeles con vaporosas telas, del mismo modo que resulta una invariante sus ensortijadas y airosas cabelleras, como también lo es la estrecha relación fisiognómica de la Santa Catalina de Baena con los tipos representados en la Sagrada Familia adorada por Santas y ángeles de una colección privada alemana ${ }^{21}$. Además de la correspondencia en las dimensiones de estas obras con el lienzo que aquí nos ocupa, otro elemento identificativo que delata la participación directa de Schut son las abigarradas guirnaldas florales de su época de juventud; una participación en estos motivos que paulatinamente se iría desentendiendo al permitir la colaboración de otros artistas más virtuosos en la ejecución de estos elementos ${ }^{22}$. Estas fieles relaciones con las primeras obras de Schut realizadas tras su regreso de Italia, permiten datar el lienzo cordobés en la órbita de 1628-1635.
Compositivamente, el lienzo muestra distintas inclinaciones en cada uno de sus tres planos, atendiendo en el central a una fiel copia de la pintura florentina, en el inferior a la adecuación de los requerimientos del diseño, visibles en los plegados de las túnicas y la gestualidad de las manos, de la que tan buena muestra nos dejó Schut en su catálogo pictórico. Mientras que la exaltación colorista y lumínica se hace presente en el rompimiento glorioso con el Niño Jesús como Salvator Mundi, del que encontramos la falsilla de donde se inspira en un dibujo propio conservado en el Rijksmuseum, lo que viene a confirmar más aún nuestra atribución (fig. 4).

\section{3. ... el rico y lucido sagrario de bronce}

De entre la documentación conventual manejada, es el manifestador ${ }^{23}$ una de las piezas que más referencias hemos encontrado, pues estuvo a la venta en numerosas ocasiones para con ello sobrevenir las calamitosas dificultades que atravesó el convento desde finales del siglo $\mathrm{XIX}^{24}$. En todas ellas se dejaba constancia expresa de la procedencia italiana, su magnífica factura y la compleja estructura arquitectónica, insistiendo 
en la variedad de materiales que lo conforman. De nuevo hemos de acudir a la bibliografía y fotografía histórica para comprobar cómo debió ser en origen, pues las vicisitudes acaecidas por el convento durante el siglo XX han mutilado en parte su original fisonomía:

Uno de los objetos más notables del catálogo de la provincia de Córdoba es el templete tabernáculo del retablo mayor de esta iglesia, labrado en bronce, mármoles y lapislázuli. Sobre una gran escalinata de bronce se levanta el templete con tres fachadas corintias, cada una de dos columnas y frontón. Encima de estas fachadas corre un ático y más alto una cúpula con linterna. Está adornado con estatuitas preciosas de los evangelistas; dos en los intercolumnios y otras dos en los vanos de las portadas laterales. Sobre los frontones de las portadas, virtudes recostadas y en el delantero, además, un pelícano, y en los otros escudos de armas. Remata en una cruz. Sobre la gradería, en los cuatro ángulos, cuatro pedestales con las estatuas de San Andrés, Santiago, San Pedro y San Pablo en bronce fundido. Los lisos de los entablamentos son placas de lapislázuli y las columnas de mármol.

Se halla colocado este templete sobre un repisón de mármol y estuco y en éste hay una bella portada de bronce y lapislázuli que sirve de depósito al Sagrario. Las hojas, o mejor dicho, la hoja de puerta es una chapa de lapislázuli y en ella se ven clavados dos ángeles de chapa dorada recortada, de modo que se dibujan sobre el fondo azul de la piedra. Están de pie, en reposo, las alas en alto, las vestiduras cayendo naturalmente y cada uno levanta un brazo para sostener un cáliz con hostia. Son un prodigio de burilado y de buen gusto y finura ${ }^{25}$. (fig. 5)

A la vista de estas informaciones, constatamos que no se conservan ni las figuras femeninas que representan las virtudes recostadas sobre los tres frontones del edículo, ni los escudos de armas en los frontones laterales ni la balaustrada con jarrones que coronaría el ático, también faltan los cuatro apóstoles alojados sobre la cornisa del orden de columnas corintias y que completarían el colegio apostólico.

La calidad de la pieza, el esmero en el acabado de todos sus elementos, así como las dimensiones del templete tabernáculo $(167 \times 112 \times 62 \mathrm{~cm})$, hicieron sugerir a Ramírez de Arellano pudieran haber surgido de manos "del famoso Jàcome
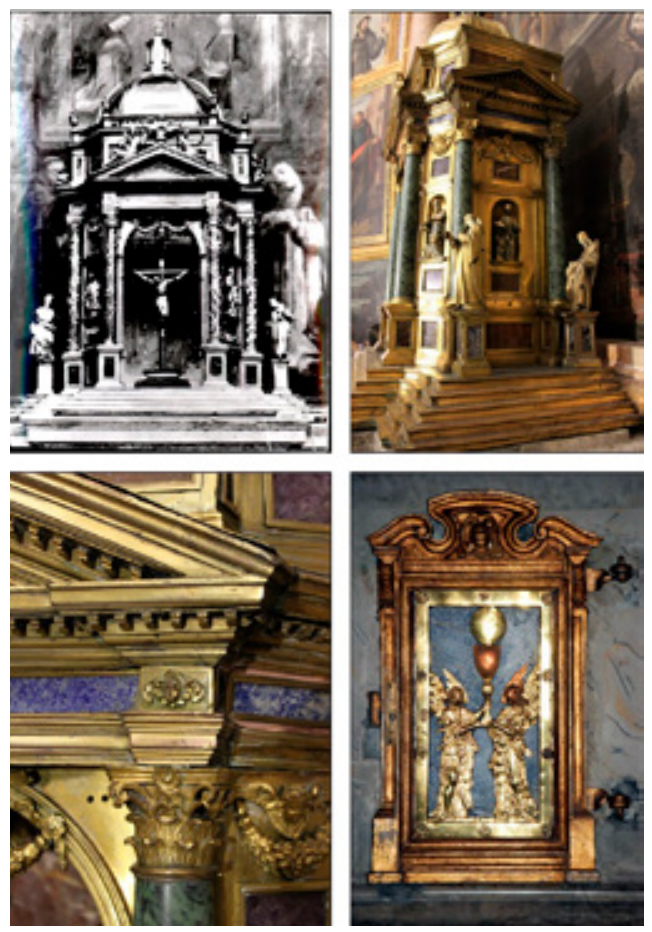

Fig. 5. Sebastiano Torrigiani y Ludovico del Duca, Tabernáculo Eucaristico y Puerta de Sagrario, ca. 1590. Bronce, mármoles y lapislázuli, manifestador: 167×112×62 cm. Convento Madre de Dios de Baena, retablo mayor. Foto superior izquierda en Biblioteca Nacional de España, Fondo Fotográfico Guerra Civil Española. Córdoba. Baena, Caja 79, foto 18r; resto fotos del autor

Trezzo" 26. Una atribución que la crítica ha secundado sin contrastar, con la clara intención de parangonar esta microarquitectura con el tabernáculo del altar mayor escurialense, pero olvidando que el artista lombardo había fijado su residencia en Madrid desde 1579 hasta su muerte en 1589. Si confiamos en las fuentes que manejamos, la adquisición de la pieza se produjo en Roma durante la embajada en la Santa Sede del V duque de Sessa ${ }^{27}$, por lo que hemos de atender a la actividad religiosa y artística que vivía la Ciudad Eterna en estos momentos. De un lado, Trento propició la atención al dogma de la transubstanciación dando lugar a una variedad de configuraciones que estimularon la evolución tipológica del altar, promoviendo la construcción de arquitecturas de mármol, jaspes y metales preciosos para los altares de las iglesias, llegando incluso a la escala monumental con la clara intención de guardar y 

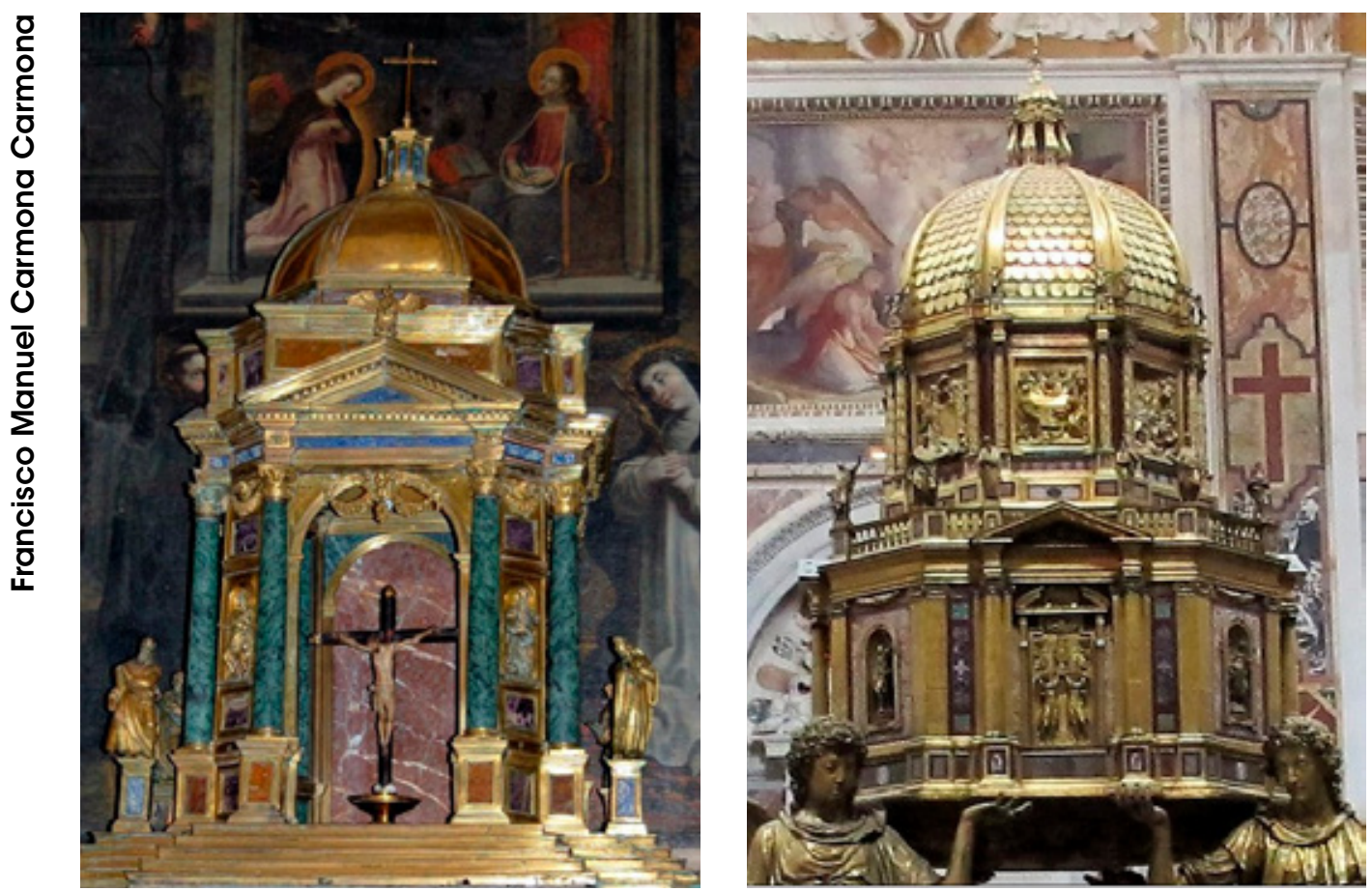

Fig. 6. Correspondencia entre los Tabernáculos Eucarísticos del convento Madre de Dios y de la Capilla del Santísimo Sacramento o Sixtina en la iglesia de Santa María Mayor de Roma. Foto: autor

exhibir con dignidad el Corpus Christiz. De otro lado, debió de servir de referencia el tabernáculo ideado por Domenico Fontana y realizado por los orfebres Sebastiano Torrigiani (†1596) y el siciliano Lodovico del Duca (†1603) para la capilla del Santísimo Sacramento -o Sixtina- en Santa Maria Maggiore de Roma29. Todo un alarde de creación artística propio de un enterramiento papal, y que, salvando las distancias, el de Sessa debió tomar como elemento referencial para magnificar su pretendido panteón familiar en Baena (fig. 6).

No en vano, el edículo romano guarda en lo estructural, material e iconográfico bastantes elementos coincidentes con el baenense. Así, mientras que la disposición centrada en la capilla papal permite configurar un tabernáculo de planta octogonal y un limpio juego de elementos arquitectónicos en bronce, en Baena la frontalidad de su disposición obliga a achaflanar sus esquinas para -ayudado del ático y la cúpula- dotarlo de cierta centralidad, compensando su menor tamaño con una mayor profusión de detalles en sus estructuras de bronce. Tanto en uno como en otro se aprovechan sus lados menores para ubicar hornacinas con las figuras de los evangelistas y sobre pedestales al resto de apostolado $^{30}$. Materialmente, la labor de taracea en piedra dura del monumento papal no se emplea en el de nuestro convento, solventándose aquí con la utilización de placas de lapislázuli y jaspes de diversos colores. Ya hemos comentado que en Madre de Dios se han perdido las figuras ubicadas sobre el ático, lo que sin duda podría ayudar a certificar la utilización de idéntico molde para la realización del apostolado. De igual modo, encontramos en ambas obras un mismo y original recurso iconográfico que decora tanto la puerta del sagrario conventual como la fachada principal del tabernáculo romano; se trata del relieve en bronce de dos ángeles que soportan un cáliz del que sobresale la Sagrada Forma. Todo esto, unido al bagaje y maestría que Torrigiani y Duca tenían en el empleo tanto del bronce como de la piedra dura, hace posible adscribir a su órbita la autoría del tabernáculo de Madre de Dios. 

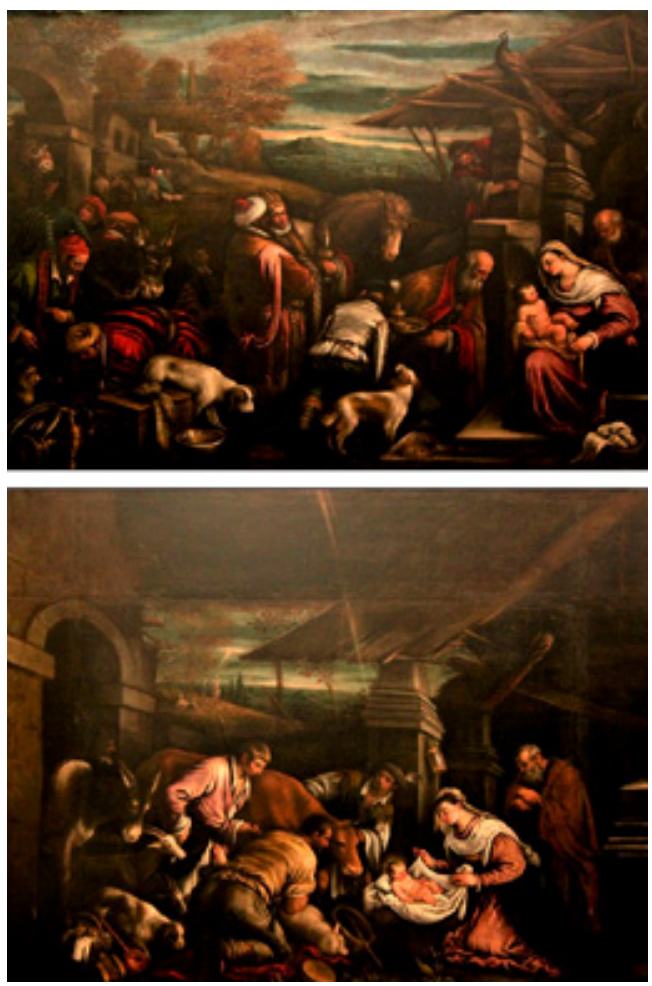

Fig. 7. Taller de los Bassano, Adoración de los Magos y Adoración de los Pastores, finales siglo XVI. Ambos óleo sobre lienzo, 145×195 cm. Convento Madre de Dios de Baena, capilla mayor. Foto: autor

\section{2. ... todos los demás cuadros grandes y pequeños, de cualquier manera que sean}

Como venimos diciendo, la decoración pictórica de la cabecera de la iglesia conventual se originó a partir de que los $V$ duques de Sessa la adquirieran como patronos perpetuos y privativos para establecer allí su sepultura y la de su descendencia. La duquesa doña Juana la embelleció con todas las piezas de valor que disponía en su capilla privada, más aquellas que desde Roma habían enviado hasta establecerse definitivamente el patronato. Se constituyó por tanto un conjunto heterogéneo de pinturas de distinta procedencia, tamaño, técnica y estilo, sin percibirse programa iconográfico alguno, respondiendo su decoración únicamente a los criterios de simetría, magnificencia y calidad de buena parte de las obras allí reunidas, entre las que destacan aquellas de indudable origen e inspiración italiana.

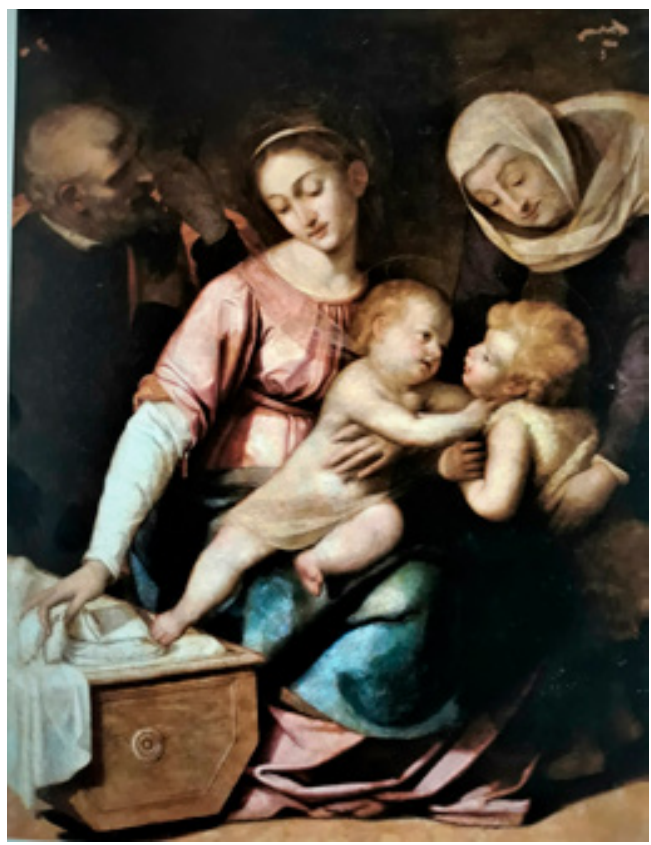

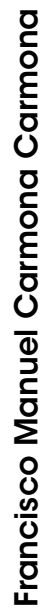

Fig. 8. Scipione Pulzone el Gaetano, Sagrada Familia con Santa Isabel y San Juanito, ca. 1588-1590. Obra firmada y datada: «Scipio Gayetano, faciebat 15...». Óleo sobre lienzo, 136×104 cm. Colección particular cordobesa. Foto: Gratia Plena, 2004

Cuenta esta capilla con dos lienzos procedentes del taller de los Bassano que representan la Adoración de los Pastores y la Adoración de los Magos (fig. 7). Así lo atestigua Ruiz Manero ${ }^{31}$ y la sintonía de calidad con otras copias y versiones de la misma composición que se encuentran en distintos museos y colecciones ${ }^{32}$. Este mismo autor señaló además en Madre de Dios una copia de la Sagrada Familia de la Galería Borghese de Roma, obra de Scipione Pulzone ${ }^{33}$, y que hoy se encuentra en una colección privada cordobesa ${ }^{34}$, (fig. 8) la misma que Burke y Cherry confirman que tuvo en Baena su origen a partir del inventario testamentario de la duquesa de Sessa en $1638^{35}$.

Además, el convento posee una serie de dieciséis planchas de cobre pintadas al óleo que representan distintos pasajes de la Vida de la Virgen y la Infancia de Jesús (fig. 9), dispuestas sin un programa aparente, lo que unido a la desigual calidad de las mismas señalan fueron ejecutadas por distintas manos. No obstante, en algunas escenas, la riqueza de matices y el tratamiento 
Huella y presencia Flamenca e Italiana en los conventos Cordobeses de Madres Dominicas
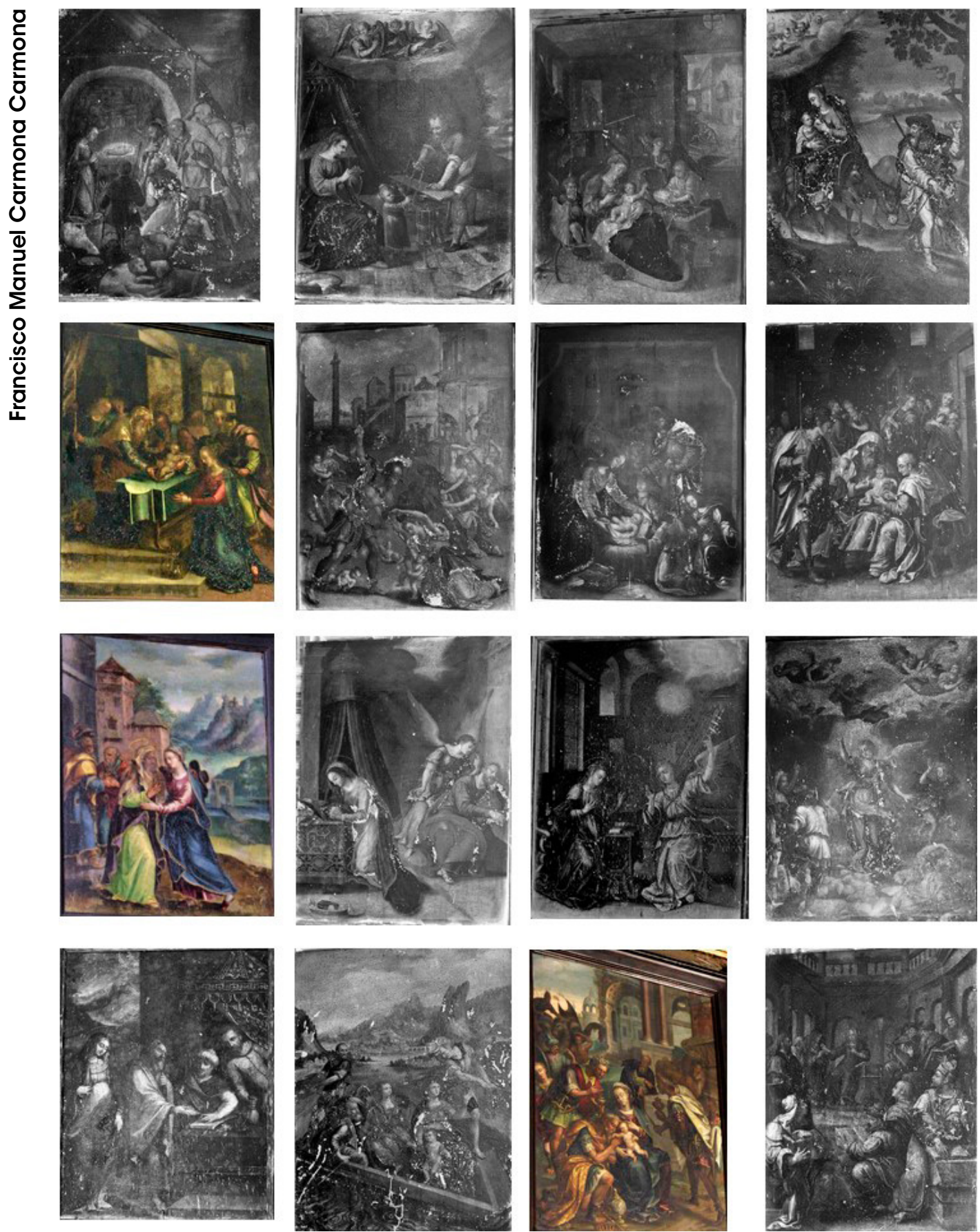

Fig. 9. Dieciséis escenas de la Vida de la Virgen y la Infancia de Cristo. Anónimas, finales s. XVI. Óleos sobre lámina de cobre, $470 \times 360 \mathrm{~mm}$. Convento Madre de Dios de Baena, capilla mayor. Fotos: Archivo Diputación Provincial de Córdoba. Catálogo Histórico Artístico Provincial, Baena, refs. A-364-258 a A-364-270; y autor 


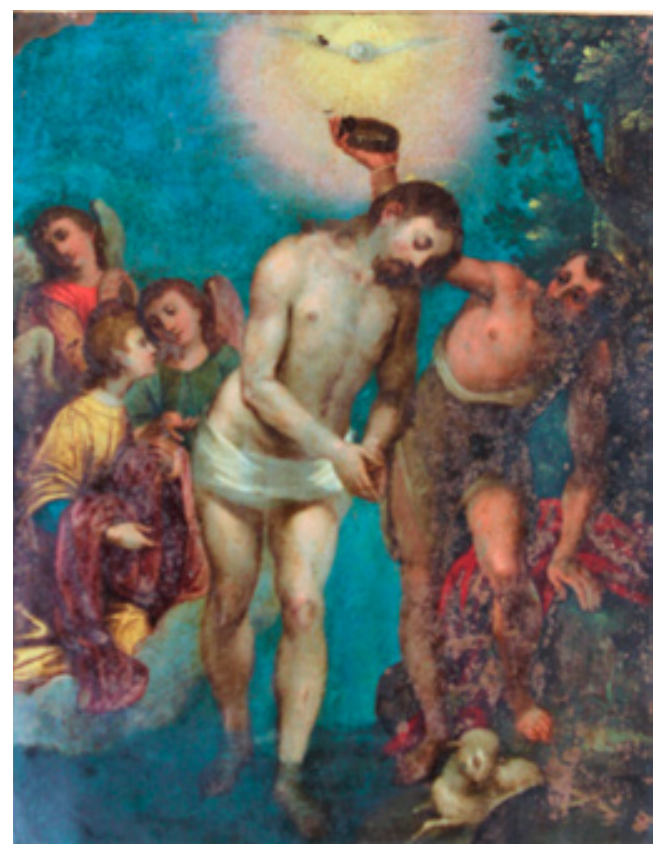

Fig. 10. Bautismo de Cristo. Anónimo, finales s. XVI. Óleo sobre lámina de cobre, $225 \times 155 \mathrm{~mm}$. Convento Madre de Dios de Baena, capilla mayor. Foto: autor

minucioso del dibujo, ejecutada cual miniatura, nos permite señalar que fueron realizadas cooperativamente por distintos miembros de un taller en un contexto de producción casi industrial, a tenor de la evidente utilización de las falsillas grabadas de los Sadeler y Wierix. Motivos suficientes que en el marco de las obras adquiridas durante la estancia romana de los duques de Sessa, pudieron haber sido escogidas entre las ofrecidas de un repertorio36. Del mismo modo, otro óleo sobre cobre que representa el Bautismo de Cristo (fig. 10), de tamaño más reducido que los anteriores $(281 \times 219 \mathrm{~mm})$, nos induce a pensar que se compró cuando ellos, más por su calidad técnica y su originalidad compositiva que por la adecuación a un pretendido discurso iconográfico. De ellas no tenemos constancia documental de su compra, pero se deduce que pudieron ser adquiridas para compensar el fuerte carácter masculino que imprimían aquellas otras de las que sí disponemos referencias de su adquisición, y que nos anuncian la temprana intención de considerar este cenobio femenino como panteón ducal.

\section{La serie Solitudo sive Vitae Patrum Ere- micolarum}

Del original retablo pictórico que decora la cabecera de la iglesia conventual de Madre de Dios la historiografía ha pasado de puntillas sobre los dos cuadros que visten sendos lados del ábside ${ }^{37}$. Cada uno de ellos contiene quince imágenes realizadas sobre lámina de cobre de 180×230 mm con la técnica del óleo y guarnecidas de ébano. Las treinta obras constituyen la representación pictórica completa de la serie grabada Solitudo sive Vitae Patrum Eremicolarum, compuesta de otras tantas planchas abiertas por los buriles de los hermanos Raphael y Johan Sadeler, siguiendo las composiciones de Marten de Vos (fig. 11).

Hasta el momento no conocemos en España colección alguna que contenga completa la versión pictórica de la Solitudo, de ahí la evidente fascinación que nos produce dar a conocer la treintena de cobres de esta serie iconográfica. Únicamente la literatura científica nos da noticia excepcional de los trece lienzos del monasterio de las Descalzas Reales de Madrid que representan otros tantos ermitaños de la Solitudo ${ }^{38}$, y las siete telas de esta misma serie que conserva el monasterio de la Anunciada de Villafranca del Bierzo ${ }^{39}$, en todas ellas señalándonos su origen italiano en la órbita de los pintores Paul Bril (1553-1626) o Jan I Brueghel (1568-1625).

Una reciente restauración de las pinturas de ermitaños de Baena ha posibilitado que luzcan cercanos a su esplendor original ${ }^{40}$, destacándose de todo el conjunto la fiel adecuación a la falsilla de Marten de Vos en la que se inspiran. Ahora son más perceptibles tanto el detallismo de su técnica, los matices atmosféricos, las veladuras como la sutil utilización de los reflejos lumínicos en la inmensidad de hojarasca boscosa. Cada pintura lleva rotulado con purpurina el nombre del ermitaño seguido del ordinal que ocupa su estampa en la serie de los Sadeler, lo que llama la atención pues la disposición de los cobres en cada cuadro aparentemente no guarda ningún orden lógico (fig. 12).

Como en los grabados, el ermitaño siempre ocupa el primer plano, habitando una monumental naturaleza que nos habla de individualidad, del rigor del ascetismo, de escasez, de búsqueda de la soledad, de peligro y, sobre todo, de reco- 

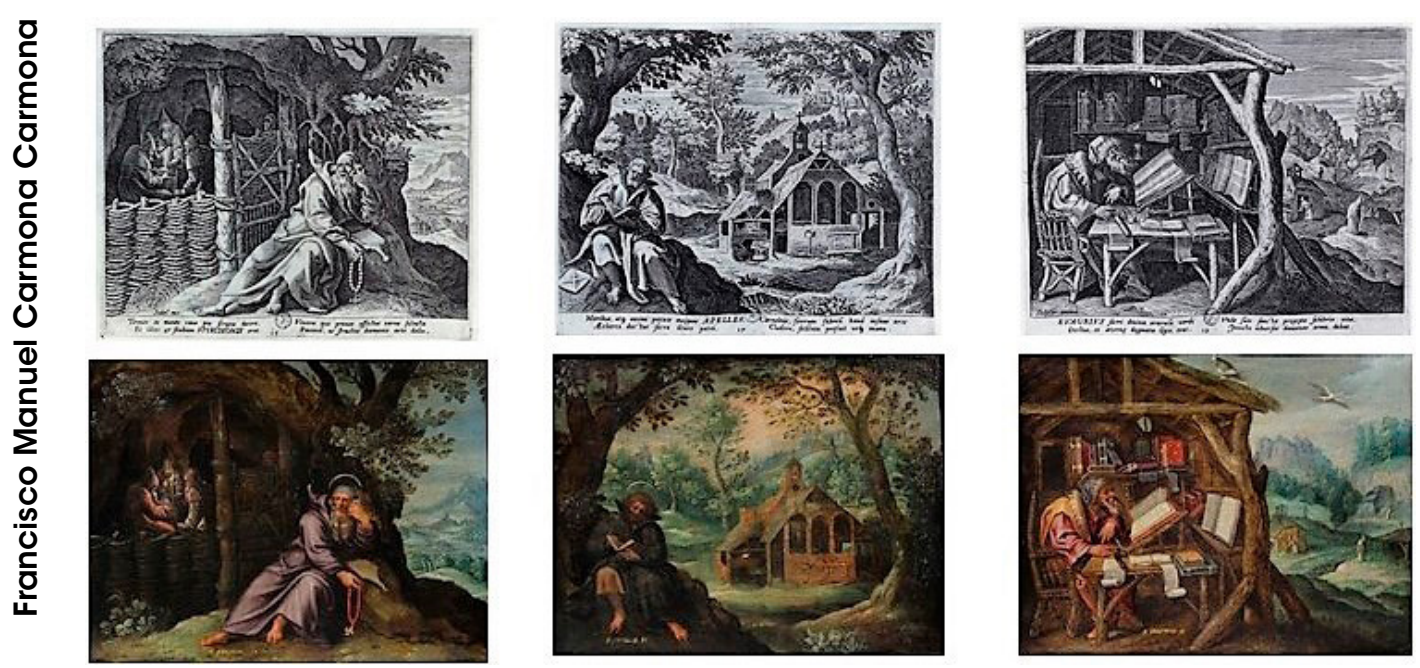

Fig. 11. Grabados de Jan Sadeler correspondientes a Espiridión, Apeles y Evagrio de Solitudo sive Vitae Patrum Eremicolarum y su correspondencia en la serie de cobres pintados de Madre de Dios. Fotos: autor

gimiento en la lectura, la meditación y la oración, en definitiva, del ideal de esa particular opción de vida. Los paisajes en perspectiva atmosférica rivalizan en protagonismo con la escena religiosa que desarrolla el anacoreta, los horizontes se delimitan por prominentes cordilleras, surcados por ríos entre los valles y la vegetación. Es aquí donde la naturaleza se humaniza con caminos, prados, lejanas estructuras edilicias o simples ruinas, donde se hace visible el hombre que habita en comunidad o, en algunos casos, la presencia de otros compañeros en el desierto eremita. El cielo rara vez se representa de tonalidad celeste, siempre densamente vaporoso o nublado, casi confundido con el límite terrestre, lo que propicia un acusado contraste con la ubicación de la escena eremítica.

En honor a la verdad, los cobres de Baena muestran sutiles divergencias respecto de su referente grabado. Así, a todos los ermitaños se les ha representado aureola de santidad, y en prácticamente todas las pinturas se enriquece el escenario incorporando una mayor presencia de fauna y flora. La intencionalidad en ello es evidente por ser manifiesto su simbolismo. Verbigracia, la lechuza incorporada sobre la mesa donde escribe San Antonio Abad, alude a su sabiduría en el argumentario para luchar contra el arrianismo de Alejandría, más que a la negación a las tentacio- nes, que ya se vale con el crucifijo y la campanilla. Los lirios blancos dispuestos en primer término nos señalan la defensa mariana, las cigüeñas que sobrevuelan el desierto eremítico nos hablan de la constante lucha contra Satán, o las tórtolas como ofrecimiento de su ascética vida a Dios. Por tanto, las golondrinas, ánades, lagartijas o las ranas que complementan las escenas señalan una adecuación a los criterios intelectuales imperantes en el momento de su realización.

Afortunadamente, de los cobres pintados de Baena tenemos referencia explícita de su compra en Roma a finales de 1592, según la anotación en el libro de gasto del V duque de Sessa: "135 moneta pagati di suo ordine a Bartolome Piselli pittore disse per prezzo di 30 quadretti delli Santi Padri dipinti in rame" ${ }^{41}$. Este apunte trata sin duda de los treinta santos padres pintados sobre cobre que don Antonio adquirió y que se encontraban en la madrileña capilla particular de su esposa en el momento de su fallecimiento ${ }^{42}$. Respecto del anónimo pintor Bartolome Piselli, todo apunta a que se trata de un marchante y que su original apellido responde a un apodo, como era costumbre emplear entre los artistas establecidos en la Ciudad Eterna, de la misma manera que los Bentvueghels acostumbrarían a denominarse en las décadas siguientes. La calidad que demuestran las pinturas de Baena obliga a pensar que 

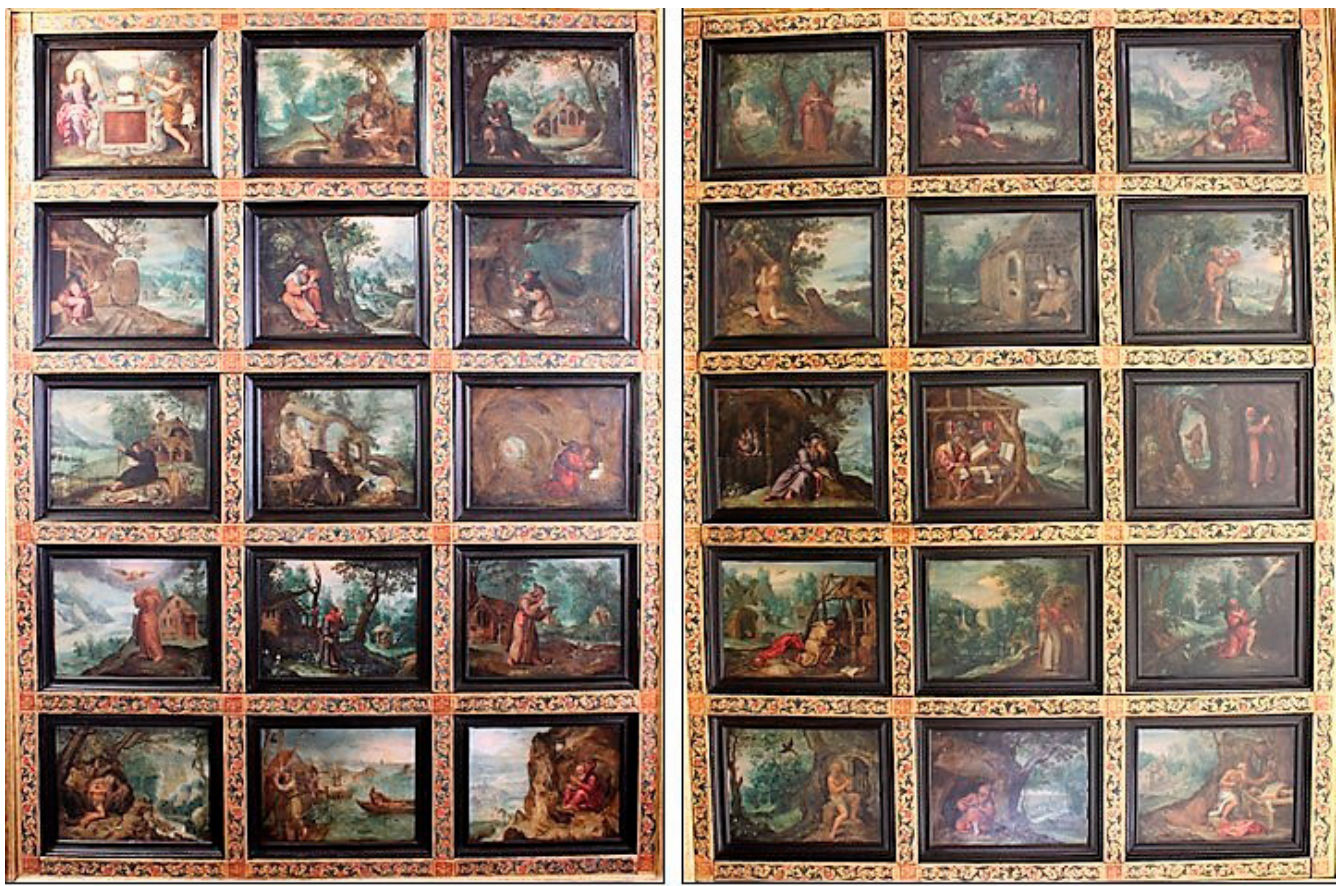

Fig. 12. Jan I Brueghel y Paul Bril, Serie pictórica completa de Solitudo sive Vitae Patrum Eremicolarum, ca. 1592. Treinta óleos sobre láminas de cobre, $\approx 180 \times 230 \mathrm{~mm}$ cada uno. Convento Madre de Dios de Baena, capilla mayor. Fotos: autor

su autoría no debió pasar desapercibida por la elitista clientela romana, y aún menos que este personaje no aparezca en ningún diccionario biográfico de artistas italianos.

No en vano, en los años siguientes a la publicación de la Solitudo (1585-1586), en Roma se estaba gestando una corriente intelectual abanderada por cuatro jóvenes cardenales: Egidio Colonna, Benedetto Giustiniani, Francesco Maria del Monte y Federico Borromeo, todos ellos ávidos coleccionistas de arte relacionado con las Ciencias Naturales en diverso grado, pero sobre todo, en una estética naturalista. Concretamente, durante la estancia de Borromeo en Roma (1587-1595) fue éste quien más favoreció con la actividad artística el acercamiento a esa belleza del mundo natural creado por Dios, pues consideraba que en el paisaje animado con escenas sagradas es donde la bondad divina expresa mejor su significado y se plasman a la perfección las inquietudes ascéticas de su ideario ${ }^{43}$. La estrecha relación y predilección de Borromeo por Paul Bril y Jan I Brueghel ${ }^{44}$ debió servir de catalizador para que estos proyectaran enormemente su actividad en la selecta sociedad romana y, sobre todo, en la ambición artística de la nobleza hispánica establecida en la ciudad papal, dado que uno y otro fueron enormemente pródigos en este género, surtiendo de pinturas a "sus insignes y cultísimos clientes, especialmente de la serie Solitudo", al tratarse de un corpus iconográfico muy recurrente para ser llevado al color en el contexto contrarreformista ${ }^{45}$.

Ayuda a nuestro ejercicio atributivo saber que Jan Brueghel en su juventud comenzó su carrera principalmente realizando abundantes trabajos a pequeña escala en soporte de cobre para poder sostener su taller y que, en $1592^{46}$, con escasos veintitrés años, se estableció en Roma donde conoció a Paul Bril47. Precisamente para estas fechas se documentan distintas obras realizadas con la misma técnica y de dimensiones similares a las de Madre de Dios. Es el caso del Paisaje con San Jerónimo de Londres, de incontestable similitud con su homónimo de Baena, salvo que el lirio introducido en la composición inglesa se susti- 


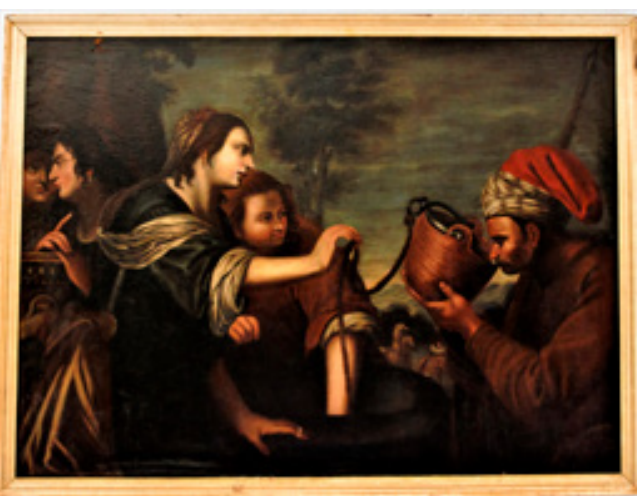

Fig. 13. Domenico Fiasella, Rebeca y Eliezer en el pozo, mediados siglo XVII. Óleo sobre lienzo, 108×147 cm. Monasterio Santa María de Gracia de Córdoba. Foto: autor

tuye en la cordobesa por un saurio. De idéntica calidad en el tratamiento del paisaje y los celajes que el San Malco de Madre de Dios es el Paisaje rocoso con San Wendelin, de mano de Brueghel en una colección privada alemana, aunque en esta versión se hayan suprimido los numerosos escorpiones que tanto en el grabado como en Baena amenazan al ermitaño, pero coincidiendo ambos en completar la representación introduciendo el símil de una solitaria ave rapaz. Unas sutiles variaciones respecto del original grabado que se argumentan como recursos invariantes del artista, como deja evidenciar en su estampa Descanso en la Huida a Egipto, compuesta por Brueghel y sacada a buril por Aegidius Sadeler en 1596, donde emplea la personal firma bruegheliana de las cigüeñas surcando el cielo. Por tanto, todo lo anterior no hace sino permitirnos adscribir al catálogo artístico de Jan Brueghel el Viejo los treinta óleos sobre cobre que representan la Solitudo sive Vitae Patrum Eremicolarum del convento de Baena.

Empero, la figura de Paul Bril queda un tanto diluida en esta atribución, aunque si atendemos a datos tangenciales que nos ofrece la historiografía artística podemos intuir cierto grado de colaboración entre ambos pintores flamencos para esta obra. Así, el profesor Bosch Ballbona nos contextualiza y detalla formidablemente la relación contractual que obliga en 1601 a Paul Bril, junto a Cobergher, Frankaert I y van Nieulandt, a realizar el formidable encargo de noventa cuadros de ermitaños y cuatrocientos retratos de

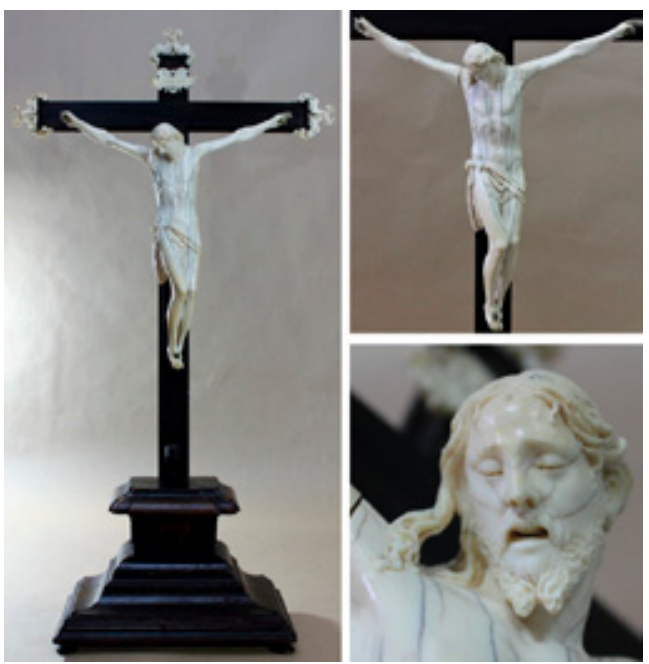

Fig. 14. Francesco Terilli, Crucificado de marfil de la priora, primer tercio siglo XVII. Marfil sobre cruz y peana de ébano, dimensiones máximas. Figura de Cristo: $265 \times 268 \times 45 \mathrm{~mm}$ (torso 58, brazo izquierdo 116, derecho 120). Cruz: patibulum $370 \times$ stipes $526 \mathrm{~mm}$. Peana: $158 \times 250 \times 148 \mathrm{~mm}$. Monasterio Santa María de Gracia de Córdoba. Fotos: autor

huomini illustri antichi para don Pedro de Toledo, $\checkmark$ marqués de Villafranca. La escritura de obligación se realiza en la residencia del duque de Sessa de la vía del Corso ${ }^{48}$, ante el notario Rabassa, cuya vinculación con el embajador se documenta desde su llegada a Roma ${ }^{49}$. Por tanto, no es descabellado pensar que Sessa ya tenía referencias de la calidad pictórica de Bril en su serie de Baena -observables en la sintonía de matices del Paisaje con Muzio de la Pinacoteca Ambrosiana ${ }^{50}$ con su homónimo de Madre de Dios-, y fuese el duque quien sugiriera a Villafranca la maestría del pintor flamenco para los cuadros que hoy conserva la Anunciada del Bierzo. De este modo se contestaría la calidad de los ascetas baenenses, resultando fácil adivinar el trabajo colaborativo de Bril y Brueghel en la infinitud de los paisajes y en los vaporosos celajes, en la monumentalidad frondosa de los desiertos anacoretas, el esmero en los planos intermedios, así como en lo minucioso de las naturalezas muertas y su relación con los personajes. 


\section{Italia en el convento Jesús Crucificado}

Jesús Crucificado fue fundado en 1506 como un hospital de mendicidad por los señores de El Carpio, y al poco se le permitió ser refundado como convento de contemplativas dominicas ${ }^{51}$. Los altos cargos ostentados al servicio de la monarquía hispánica por los Haro-Sotomayor, unido a su continuada autoridad en el concejo de la ciudad, propiciaron que Jesús Crucificado fuese un convento altamente aristocrático, donde gran parte del patrimonio artístico de esta comunidad se logra a través de los bienes privativos de las religiosas. Pero las vicisitudes atravesadas desde la invasión napoleónica hasta su exclaustración por la Gloriosa diezmaron el patrimonio de Jesús Crucificado, y el que se conservó, fue disperso acompañando a las religiosas reunidas en otros claustros $^{52}$. De entre ellos, destacamos dos piezas de indudable origen italiano y calidad artística.

\subsection{Rebeca y Eliezer en el pozo}

El refectorio del monasterio cordobés de Madres Dominicas de Santa María de Gracia lo preside el lienzo que representa la escena narrada en Génesis, 24 del encuentro de Rebeca y Eliezer en el pozo $(108 \times 147$ cm) (fig. 13). Una versión de este mismo asunto en la catedral hispalense, de similares dimensiones, incontestable parecido compositivo e idéntica resolución en el color y la iluminación, la hacen obra probable del pintor Domenico Fiasella, il Sarzana (1589-1669), lo que nos animó a seguir esta referencia en la atribución de la tela cordobesa.

De este pintor de la escuela genovesa del siglo XVII, Pérez Sánchez y Donati nos informan de la abundante obra suya enviada a España desde el puerto de Génova y de su estilo afincado aún en el manierismo pese a percibirse sugerencias flamencas y caravaggiescas ${ }^{53}$. También resaltan del cuadro sevillano "la fina calidad pictórica de la mujer del centro de la composición" ${ }^{54}$, cuya fisiognomía coincide con el mismo personaje representado en el lienzo cordobés y de quien encontramos los mismos rasgos coincidentes en otras obras seguras de il Sarzana. Ayudan a esta atribución los retratos de perfil de los personajes, utilizados casi abusivamente por Fiasella, y la composición de escenas del Antiguo Testamento a partir de medias figuras dispuestas todas ellas en un primer plano y dotadas de profundidad en un hábil juego lumínico. Por su sintonía en la gestualidad y parecido físico, en estos personajes casi en penumbra es donde más se demuestra la autoría de este pintor. Pese a conservar plenamente la apariencia decorativa y las características inherentes a Fiasella, la obra cordobesa parece demostrar el cansancio propio de una réplica tardía en una composición muy demandada por el mercado extranjero, pudiéndola datar en el promedio de siglo ${ }^{55}$.

No debemos subestimar la sugerencia dada por Burke y Cherry 56 , y aplaudida por Boccardo ${ }^{57}$, sobre el pago de legados comprometidos con anterioridad a través de los bienes artísticos sometidos a almoneda del VII marqués de El Carpio. No obstante, nosotros somos del parecer que el lienzo debió tener entrada en Jesús Crucificado como regalo de profesión de los marqueses de Escalonias a su hija sor Catalina de Jesús María, quien tomó velo negro en julio de 1697, predicándole sermón el afamado orador fray Francisco de Posadas (1644-1713, beatificado en 1818), quien con intención de instruirla comparó a la profesa con la matriarca bíblica ${ }^{58}$. Una ocasión perfecta para dejar en el convento perpetua memoria de religiosa tan significada.

\subsection{Crucificado de la priora de marfil}

A tenor de la información archivística, la presencia de crucificados de marfil en los conventos de dominicas cordobesas fue cuanto menos notable, aunque esta realidad no se constata en la actualidad. No obstante, en el monasterio de Santa María de Gracia se conserva una pieza que tradicionalmente ha permanecido en el despacho prioral, y que dada su calidad nos permite señalarla como obra italiana, de estilo semejante a las realizadas por Francesco Terilli (†1635), o Terillus como refiere Margarita Estella ${ }^{59}$. Esta autora nos da las claves para poder considerar la pieza ebúrnea como de mano de este autor y datarla en el momento cumbre de su producción.

El crucificado de la priora (fig. 14) representa la figura de Cristo expirante, en el último estertor de su agonía, mide $265 \times 268 \times 45$ mm, va cubierto con paño de pureza y está unido a la cruz con tres clavos. Tiene pérdidas en los dedos de su mano derecha y parte de la soga que sujeta el paño de pureza, sugiriendo estaba anudada con una media lazada. No va coronado de espinas, aun- 
que los testigos sobre su testa indican pudo ser exenta o de otro noble material. La cruz es plana, de ébano, con cantoneras y cartela también de marfil, faltándole el calvario en la parte baja del stipes. La figura de Cristo es estilizada, anatómicamente bien proporcionada y de musculatura nada exagerada. La habilidad de Terilli en el uso del trépano le permite realizar minuciosamente cabeza, manos, pies y paño de pureza, así como marcar lo suficiente los vasos sanguíneos del cuello y los tendones de los brazos. En la cabeza es donde se desarrolla con más brío técnico y compositivo este artista. Inclinada hacia la izquierda, muestra ojos entornados, nariz fina, barba y bigote trabajados simétricamente en pequeños rizos ensortijados y boca entreabierta, dejando ver dientes y parte de la lengua. La cabellera se dispone en dos crenchas levemente onduladas, retirada hacia atrás dejando ver la oreja izquierda y cayendo en bucle corto sobre el hombro derecho, siendo éstas características reconocibles en las obras documentadas del artista, como también lo son la sangre que brota del costado en forma de gallones y el tratamiento de los pliegues del paño de pureza ${ }^{60}$.

La obra pudo proceder del extinto convento Jesús Crucificado, y que la dispersión de obras artísticas conventuales le haya hecho ir a presidir el despacho prioral de Santa María de Gracia. El demostrado origen italiano y la calidad de la pieza hacen suponer se tratara de un regalo a la comunidad o bien un encargo de ésta, tal como se desprende de la siguiente anotación: "Tiene el convento un Sto. Cristo de marfil con indulgencia plenaria para la hora de la muerte. Lo trajo de Roma el racionero don Juan Moreno, año de $1679 " 61$.

\section{A modo de conclusión}

Solo nos resta añadir que hemos contribuido a incrementar el catálogo de obras de distintos artistas italianos, como los broncistas Torrigiani y del Duca, el escultor Terillus o el pintor genovés Fiasella. También hemos señalado la paternidad de los pintores de origen flamenco Cornelis I Schut, Paul Bril y Jan I Brueghel en distintas piezas, todas ellas poseedoras de las características intrínsecas del repertorio artístico de sus autores. Paralelamente, hemos destacado que los conventos de Madre de Dios -con los Fernández de Córdoba de la Casa de Cabra-Sessa-Baena-, y de Jesús Crucificado -con los Haro-Sotomayor, marqueses de El Carpio, que con el tiempo entroncarán con la Casa de Alba y asumirán su patronato-, al estar fundados y patrocinados por la alta nobleza española, participaron muy activamente de las manifestaciones magnificentes de estas familias privilegiadas, fueron considerados lugares estratégicos en sus políticas de prestigio y, al surtirlos de piezas artísticas de origen foráneo de excelente factura, ayudaban a señalar y reforzar su preeminencia social y económica. 
NOTAS

1 Fernando Checa Cremades, "El Bosco, los pintores flamencos y el Arca de Noé," in De El Bosco a Tiziano. Arte y Maravilla en El Escorial (Madrid: Patrimonio Nacional, 2013), 251-261. Eike D. Schmidt, "Spagna e Italia: una costante osmosi culturale," in Spagna e Italia in dialogo nell'Europa del Cinquecento, edited by Faietti, Gallori and Mozzati (Firenze: Uffizi, 2018), 9-11.

2 Archivo Histórico de la Nobleza, Toledo (AHNOB). [Fondo] Baena, Caja (C.) 12, Documento (D.) 5, Libro de despachos, folio (f.) 35v. Roma 16/01/1593.

3 Sobre los ardides empleados por el matrimonio ducal para la materialización del patronato de esta iglesia conventual nos hemos ocupado en: Francisco Manuel Carmona Carmona. 2019. "Parámetros nobiliarios y política de prestigio en el convento Madre de Dios de Baena (Córdoba)." Hispania Sacra 143: 197-202. Las adaptaciones de la capilla mayor acometidas por su hijo Luis, VI duque de Sessa, las damos a conocer en 2017b. "Obra y proyectos del gran cantero Luis González Bailén." Anales de Historia del Arte 27: 106-10.

${ }^{4}$ Archivo Conventual Madre de Dios, Baena (ACMDB), C. 1, Libro de la Hacienda, f. 271 r.

${ }^{5}$ Sobre este personaje nos ocupamos en Carmona, "Parámetros nobiliarios y política de prestigio...," 204

${ }^{6}$ AHNOB. Baena, C. 127, D. 208213, Testamento de doña Juana Fernández de Córdoba Cardona Aragón, f. 12v. Madrid 27/03/1634.

7 AHNOB. Baena, C.12, D.5, Libro de despachos, f. 36v. Roma 22/12/1593.

${ }^{8}$ Los pormenores del proyecto funerario del VI duque de Sessa en: Francisco Manuel Carmona Carmona. 2017a. "El frustrado proyecto para panteón y sepulcro del duque de Sessa en Baena." Archivo Español de Arte 357: 19-30; y en Carmona, "Obra y proyectos del gran cantero Luis González Bailén," 90-6.

${ }^{9}$ AHNOB. Baena, C.23, D.10, Estafeta de Luis González al duque de Sessa, f. 1r. Cabra 14/12/1633.

${ }^{10}$ Jesús Rivas Carmona, Arquitectura y policromía. Los mármoles del
Barroco andaluz (Córdoba: Diputación, 1990), 7-13.

${ }^{11}$ José Luis Barrio Moya. 1983. "Bartolomé Román tasa dos cuadros de Scipión Pulzone y otro de Juan de Jáuregui." Archivo Español de Arte 224: 407-8.

${ }^{12} \mathrm{ACMDB}, \mathrm{C.6}$, Informe de restauración, 01/09/2001.

${ }^{13}$ Blanca González Talavera, "Presencia y mecenazgo español en la Florencia medicea: de Cosme I a Fernando I." PhD diss. (Universidad de Granada, 2012)

${ }^{14}$ (sic) «A doña Mariana de Córdoba, mi nieta, le dejo [...] un cuadro pequeño de la Anunciata de Florencia», AHNOB. Baena, C. 127, D. 208, Testamento de doña Juana Fernández de Córdoba Cardona Aragón, f. 12v. Madrid 27/03/1634. José Luis Barrio Moya. 1984. "La librería y otros bienes de la duquesa de Sessa (1638)." Cuadernos de Bibliofilia, 50.

${ }^{15}$ Cristina Acidini, La primavera perfetta. Storia dei fiori a Firenze tra arte e scienza (Firenze: Le Lettere, 2010), 137-44

${ }^{16}$ Analizado por María Paz Aguiló Alonso, "El papel de los mercaderes en el comercio de arte entre España y los Países Bajos," in Comunidades transnacionales: colonias de mercaderes extranjeros en el mundo atlántico (1500 1830) (Madrid: Doce Calles, 2010), 209-49.

${ }^{17}$ Entre las gradas que dan acceso al presbiterio de la capilla mayor conventual se alojan tres lápidas en mármol negro, que corresponden al matrimonio ducal y su hijo don Gonzalo. Las epigrafías están transcritas por Francisco Valverde y Perales, Historia de la villa de Baena. (Toledo, 1903), 328-330.

${ }^{18}$ Gertrude Wilmers, Cornelis Schut (1597-1655): A Flemish Painter of the High Baroque (Leuven-Antwerpen: Brepols, 1996), 3.

${ }^{19}$ La clientela agradecía referencias explícitas a Caravaggio, Guido Reni o Domenichino, aunque revelando "an increased awareness of Rubens's work that would have been impossible for any artist working in Antwerp to avoid". Wilmers, Cornelis Schut..., 32. Pese a esto, "Schut trabajó de manera independiente en grandes retablos para las iglesias de Flandes, produjo pinturas de contenido religioso y profano para patronos privados, decoró numerosas guirnaldas de flores y frutas, destacó especialmente por su abundante obra grabada, diseñó cartones para tapices e incluso platerías". Jahel Sanzsalazar. 2013. "Cornelis Schut: Nuevas pinturas identificadas en Bélgica y España." Archivo Español de Arte 343: 203.

${ }^{20}$ Wilmers, Cornelis Schut..., 74-75 y 351 (Cat. A12; 176×151 cm); 90 y 358 (Cat. A24; 150×205 cm) respectivamente.

${ }^{21} \mathrm{Ibid} ., 100-101$ y 364 (Cat. A38; $235 \times 200 \mathrm{~cm}$ ).

${ }^{22}$ Ibid., 53-55.

${ }^{23}$ Obligado es atender a las precisiones terminológicas sugeridas por Martín González, quien nos anuncia que tras Trento se hizo hincapié en el culto de adoración a la Eucaristía y determinándose se dispusiera de una custodia en medio del altar mayor para el Santísimo Sacramento, y en los sagrarios se pusieran los santos óleos. Juan José Martín González. 1998. "Sagrario y manifestador en el retablo barroco español." Imafronte 12: 25-32.

${ }^{24}$ Archivo General Obispado de Córdoba, C. 6.804, Súplica de autorización para vender algunos objetos del convento $y$ atender a urgente reparaciones, Baena 24/03/1899.

${ }^{25}$ Rafael Ramírez de Arellano y Díaz de Morales, Inventario monumental y artístico de la provincia de Córdoba (Córdoba: Diputación, 1983), 575.

${ }^{26} \mathrm{lbid}, 575$

${ }^{27}$ Abad de Rute, Historia y descripción de la antigüedad y descendencia de la Casa de Córdoba (Córdoba: Real Academia, 1954), 215. ACMDB, C.1, Libro de la Hacienda, f. 271r.

${ }^{28}$ Gabriele Guadagna. 2016. "Reca stupore al tempo - Riflessioni sui tabernacoli in lapislazzuli a Palermo tra tarda maniera e neoclassicismo," Rivista dell'Osservatorio per le Arti Decorative in Italia 14: 65.

${ }^{29}$ El tabernáculo de bronce dorado fue realizado entre 1587 y 1589 . Frits Scholten, European Sculpture and metalwork (New York: Metropolitan Museum of Art, 2011), 48 
${ }^{30}$ Las figuras de los apóstoles Pedro, Andrés, Santiago y Pablo miden un promedio de $225 \mathrm{~mm}$ de alto, siendo los ubicados en los extremos sobre pedestales.

${ }^{31}$ José María Ruiz Manero, Los Bassano en España (Madrid: FUE, 2011), 366.

${ }^{32}$ Verbi gracia, la copia fiel de la Galería Borghese, la epifanía de idénticas dimensiones del Museo de Arte de Viena o la vertical versión del Museo del Prado, para el caso de la Adoración de los Magos; mientras que de la Adoración de los Pastores encontramos copias en diferentes dimensiones en el Museo de Brescia y la Galería Alfonsi de Vicenza.

${ }^{33}$ José María Ruiz Manero. 1995. "Obras y noticias de Girolamo Muziano, Marcello Venusti y Scipione Pulzone en España," Archivo Español de Arte 272: 376.

${ }^{34}$ Gratia Plena. La llena de Gracia, Catálogo de exposición (Córdoba: CajaSur, 2004), 242-5.

${ }^{35}$ Marcus B. Burke and Peter Cherry, Collections of Paintings in Madrid, 1601-1755 (Los Ángeles: The J. Paul Getty, 1997), 21.

${ }^{36}$ Barrio Moya, "La librería y otros bienes...," 50 .

${ }^{37}$ Valverde y Perales, Historia de la villa de Baena, 326. Ramírez de Arellano, Inventario monumental..., 575. Alberto Villar Movellán, Guía artística de la provincia de Córdoba (Córdoba: Universidad, 1995), 489. D. Ortiz, J. Bernier, M. Nieto and F. Lara, Catálogo artístico y monumental de la provincia de Córdoba (Córdoba: Diputación, 1981), 187.
${ }^{38}$ Ana García Sanz and Juan Martínez Cuesta. 1991. "La serie iconográfica de ermitaños del Monasterio de las Descalzas Reales," Cuadernos de Arte e Iconografía 7: 291-304.

${ }^{39}$ Joan Bosch Ballbona. 2008. "Paul Bril, Wenzel Cobergher, Jacob Frankaert I, Willem I van Nieulandt y los ermitaños de Pedro de Toledo, $V$ marqués de Villafranca," Locus amoenus 9: 127-154.

${ }^{40}$ Fundación Cajasur-Palacio de Viana, Taller de Restauración, Intervención 137 y 157. Córdoba 21/05/2010.

${ }^{41}$ AHNOB. Baena, C.12, D.5, Libro de despachos, f. 35v. Roma 18/12/1592.

${ }^{42}$ Barrio Moya, "La librería y otros bienes...," 50, "treinta quadros de ermitaños en lamina con su moldura de ebano, $6100 \mathrm{rs}^{\prime \prime}$.

${ }^{43}$ Pamela M. Jones. 1988. "Federico Borromeo as a Patron of Landscapes and Still Lifes: Christian Optimism in Italy ca. 1600," Art Bulletin, 70 (2): 261-72.

${ }^{44}$ Ibid., 262, 265.

${ }^{45}$ Bosch Ballbona, "Paul Bril...," 138.

${ }^{46}$ The Brueghel Family Database: <http://www.janbrueghel.net/> [Consulta: 24/06/2018].

${ }^{47} \mathrm{El}$ inicio de la colaboración entre Paul Bril y Jan I Brueghel debió iniciarse nunca antes de 1591 y necesariamente en Roma. Stefania Bedoni, Jan Brueghel in Italia e il Collezionismo del Seicento (Firenze-Milano: Pierluigi De Vecchi, 1983), 38 154.

${ }^{48}$ Bosch Ballbona, "Paul Bril...,"

${ }^{49}$ AHNOB. Baena, C.12, D.5, Libro de despachos. Roma 07/07/1592. 139.

${ }^{50}$ Bosch Ballbona, "Paul Bril...,"

${ }^{51}$ Archivo Federación Nuestra Señora del Rosario (AFNSR), C. 6, Carpeta 4, Parecer jurídico sobre patronato $y$ dotes. Córdoba 24/01/1739.

${ }^{52}$ Francisco Manuel Carmona Carmona. 2018. "Origen y evolución arquitectónica de los conventos cordobeses de Madres Dominicas," De Arte. Revista de Historia del Arte 17: 36-40.

${ }^{53}$ Alfonso E. Pérez Sánchez, Pintura italiana del siglo XVII en España (Madrid: Valdecilla, 1965), 533-534. Alfonso E. Pérez Sánchez, "Pintura genovesa en España en el Seicento." In España y Génova. Obras, artistas y coleccionistas, edited by Boccardo, Colomer and Di Fabio (Madrid: Fundación Carolina, 2004), 180. Piero Donati, Domenico Fiasella, il Sarzana (Génova: Stringa, 1974), 45113.

${ }^{54}$ Pérez Sánchez, Pintura italiana..., 544.

${ }^{55}$ Donati, Domenico Fiasella..., 48.

${ }^{56}$ Burke and Cherry, Collections of Paintings..., 831.

${ }^{57}$ Piero Boccardo, "Virreyes y Financieros. Mercado artístico y colecciones entre Madrid y Génova, siglos XVII y XVIII," in España y Génova. Obras, artistas y coleccionistas, edited by Boccardo, Colomer and Di Fabio (Madrid: Fundación Carolina, 2004), 180.

${ }^{58}$ Biblioteca Nacional, VE/188/13.

${ }^{59}$ Margarita M. Estella Marcos, La escultura barroca de marfil en España (Madrid: CSIC, 1984), v.2, 54.

${ }^{60}$ Estella Marcos, La escultura barroca..., v.1, figs. 86-88.

${ }^{61}$ AFNSR, Cajón 5, libro 3, Libro de posesiones, f. XIIIV. 


\section{REFERENCIAS}

Abad de Rute. 1954. Historia y descripción de la antigüedad y descendencia de la Casa de Córdoba. Córdoba: Real Academia.

Acidini, Cristina. 2010. La primavera perfetta. Storia dei fiori a Firenze tra arte e scienza. Firenze: Le Lettere.

Aguiló Alonso, María Paz. 2010. “El papel de los mercaderes en el comercio de arte entre España y los Países Bajos." In Comunidades transnacionales: colonias de mercaderes extranjeros en el mundo atlántico (1500-1830), 209-249. Madrid: Doce Calles. URl: http://hdl. handle.net/10261/23553.

Barrio Moya, José Luis. 1983. "Bartolomé Román tasa dos cuadros de Scipión Pulzone y otro de Juan de Jáuregui." Archivo Español de Arte 224: 407-8.

Barrio Moya, José Luis. 1984. "La librería y otros bienes de la duquesa de Sessa (1638)." Cuadernos de Bibliofilia 12: 41-51.

Bedoni, Stefania. 1983. Jan Brueghel in Italia e il Collezionismo del Seicento. Firenze-Milano: Pierluigi De Vecchi.

Boccardo, Piero. 2004. "Virreyes y Financieros. Mercado artístico y colecciones entre Madrid y Génova, siglos XVII y XVIII." In España y Génova. Obras, artistas y coleccionistas, edited by Boccardo, Colomer and Di Fabio, 189-204. Madrid: Fundación Carolina.

Bosch Ballbona, Joan. 2008. "Paul Bril, Wenzel Cobergher, Jacob Frankaert I, Willem I van Nieulandt y los ermitaños de Pedro de Toledo, $\checkmark$ marqués de Villafranca." Locus amoenus 9: 127-154. DOI: https://doi.org/10.5565/rev/ locus. 185

Burke, Marcus B., and Peter Cherry. 1997. Collections of Paintings in Madrid, 1601-1755. Los Ángeles: The J. Paul Getty Trust.

Carmona Carmona, Francisco Manuel. 2017a. "El frustrado proyecto para panteón y sepulcro del duque de Sessa en Baena." Archivo Español de Arte 357: 19-30. DOI: https://doi. org/10.3989/aearte.2017.02

Carmona Carmona, Francisco Manuel. 2017b. "Obra y proyectos del gran cantero Luis Gon- zález Bailén." Anales de Historia del Arte 27: 83-112. DOI: https://doi.org/10.5209/ anha. 57483

Carmona Carmona, Francisco Manuel. 2018. "Origen y evolución arquitectónica de los conventos cordobeses de Madres Dominicas." De Arte. Revista de Historia del Arte 17: 25-42. DOI: https://doi.org/10.18002/da.v0i17.5439

Carmona Carmona, Francisco Manuel. 2019. "Parámetros nobiliarios y política de prestigio en el convento Madre de Dios de Baena (Córdoba)." Hispania Sacra 143: 191-208. DOI: https://doi.org/10.3989/hs.2019.014

Checa Cremades, Fernando. 2013. "El Bosco, los pintores flamencos y el Arca de Noé." In De El Bosco a Tiziano. Arte y Maravilla en El Escorial, 251-61. Madrid: Patrimonio Nacional.

Donati, Piero. 1974. Domenico Fiasella, il Sarzana. Génova: Stringa.

Estella Marcos, Margarita M. 1984. La escultura barroca de marfil en España. 2 vols. Madrid: CSIC.

Falomir Faus, Miguel. 2001. Los Bassano en la España del Siglo de Oro. Madrid: Museo del Prado.

García Sanz, Ana, and Juan Martínez Cuesta. 1991. "La serie iconográfica de ermitaños del Monasterio de las Descalzas Reales." Cuadernos de Arte e Iconografía 7: 291-304.

González Talavera, Blanca. 2012. “Presencia y mecenazgo español en la Florencia medicea: de Cosme I a Fernando I." PhD diss., Universidad de Granada. https://doi.org/10.5209/ rev_anha.2013.v23.41923

Gratia Plena. 2004. Gratia Plena. La llena de Gracia. Catálogo de exposición. Córdoba: CajaSur.

Guadagna, Gabriele. 2016. "Reca stupore al tempo - Riflessioni sui tabernacoli in lapislazzuli a Palermo tra tarda maniera e neoclassicismo." Rivista dell'Osservatorio per le Arti Decorative in Italia 14: 65-82.

Jones, Pamela M. 1988. "Federico Borromeo as a Patron of Landscapes and Still Lifes: Christian Optimism in Italy ca. 1600." Art Bulletin, 70 (2): 261-272. https://doi.org/10.1080/000430 79.1988.10788565 
Huella y presencia Flamenca e Italiana en los conventos Cordobeses de Madres Dominicas

Martín González, Juan José. 1998. "Sagrario y manifestador en el retablo barroco español." Imafronte 12: 25-50.

Ortiz Juárez, D., Bernier Luque, J., Nieto Cumplido, M., and F. Lara Arrebola. 1981. Catálogo artístico y monumental de la provincia de Córdoba, tomo 1. Córdoba: Diputación.

Pérez Sánchez, Alfonso E. 1965. Pintura italiana del siglo XVII en España. Madrid: Valdecilla.

Pérez Sánchez, Alfonso E. 2004. "Pintura genovesa en España en el Seicento." In España y Génova. Obras, artistas y coleccionistas, edited by Boccardo, Colomer and Di Fabio, 177-88. Madrid: Fundación Carolina.

Ramírez de Arellano y Díaz de Morales, Rafael. 1904. Inventario monumental y artístico de la provincia de Córdoba [Manuscrito], 2 vols. Consultado el recurso digital accesible a través de http://aleph.csic.es/. Existe edición impresa editada por la Diputación cordobesa en 1983.

Rivas Carmona, Jesús. 1990. Arquitectura y policromía. Los mármoles del Barroco andaluz. Córdoba: Diputación.

Ruiz Manero, José María. 1995. “Obras y noticias de Girolamo Muziano, Marcello Venusti y Scipione Pulzone en España." Archivo Español de Arte 272: 365-80.
Ruiz Manero, José María. 2011. Los Bassano en España. Madrid: FUE.

Sanzsalazar, Jahel. 2013. "Cornelis Schut: Nuevas pinturas identificadas en Bélgica y España." Archivo Español de Arte 343: 201-20. DOI: https://doi.org/10.3989/aearte.2013.v86. i343.547

Schmidt, Eike D. 2018. "Spagna e Italia: una costante osmosi culturale." In Spagna e Italia in dialogo nell'Europa del Cinquecento, edited by M. Faietti, C.T. Gallori, and T. Mozzati, 9-11. Firenze: Uffizi. https://doi.org/10.1344/ actaartis.6.2018.27504

Scholten, Frits. 2011. European Sculpture and metalwork. New York: Metropolitan Museum of Art.

The Brueghel Family Database. "Brueghel Family: Jan Brueghel the Elder." Berkeley: University of California. http://www. janbrueghel.net. https://doi.org/10.1093/ benz/9780199773787.article.b00027549

Valverde y Perales, Francisco. 1903. Historia de la villa de Baena. Toledo.

Villar Movellán, Alberto. 1995. Guía artística de la provincia de Córdoba. Córdoba: Universidad.

Wilmers, Gertrude. 1996. Cornelis Schut (15971655): A Flemish Painter of the High Baroque. Leuven-Antwerpen: Brepols. 